\title{
An experimental investigation of existential sentences and cognitive/semantic categories in Turkish
}

Engin Arik ${ }^{1}$, Beril T. Arik ${ }^{2}$

${ }^{1}$ Psychology, Isik University, Turkey

${ }^{2}$ English, Purdue University, USA

https://doi.org/10.36505/ExLing-2012/05/0003/000209

\begin{abstract}
In this study, we investigated the relationship between two fundamental cognitive/semantic categories, Figure (F) and Ground (G), in Turkish existential sentences. We created a scale in which F-G relations were constructed with sagittal configurations such as 'There is a mouse in front of an elephant.' We asked Turkish native speakers to judge these sentences. Repeated measures ANOVA showed that participants judged the $F<G$ sentences with higher ratings compared to the $F>G$ sentences and they rated the $\mathrm{F}<\mathrm{G}$ sentences with 'in front of' the highest while the $\mathrm{F}>\mathrm{G}$ sentences with 'in front of' the lowest. This finding provides evidence for the F-G relations in Turkish existential sentences.
\end{abstract}

Key words: Existentials, Figure-Ground, Turkish.

\section{Introduction}

Existential constructions such as (1) are related to both locatives and possessives. Their underlying structure is presumably related to locatives (Freeze 1992). Previous research has shown that in (1) 'there' is the subject, copula 'be' is the predicate, 'a glass' is the pivot, and 'on the table' is the coda (Barwise and Cooper 1981; Freeze 1992; Keenan 1987; McNally 1992; Milsark 1974; Stowell 1978; for a summary see Francez 2009 and McNally 2011).

(1) There is [a glass $]_{\text {pivot }}$ [on the table $]_{\text {coda }}$

According to Zucchi (1995) and Keenan (2003), the pivot, 'a glass' in (1) cannot be marked with 'the' because the pivot should be indefinite in existential sentences. The pivot also introduces a new discourse referent (see Heim 1987; Enc 1991). In the present study, we explore whether the semantic/cognitive relationship between the pivot and the coda make a difference in existential constructions. To our knowledge, this research is the first attempt to investigate this topic utilizing an experimental linguistic methodology.

Talmy (2000) suggested that there are two fundamental cognitive-semantic categories in Conceptual Semantics, Figure (F) and Ground (G), that posit existence Fs are entities that need anchoring whereas $G$ are entities that does the anchoring. Semantic typological studies have shown that there is an asymmetrical relationship between $F$ and $G$ in languages which may

ExLing 2012: Proceedings of 5th Tutorial and Research Workshop on Experimental Linguistics, 27-29 August 2012, Athens, Greece 
also be reflected in cognition (Levinson 2003). Fs are moving or conceptually movable, more salient and smaller whereas Gs are relatively stable and bigger and can be culturally significant (Svorou 1994; Talmy 1987, 2000). In a series of studies, we are testing these hypotheses in locatives and existentials. Here, we investigated F-G relations and sagittal configurations (front-back) in Turkish existential sentences by employing acceptability judgments.

One expects that existential 'there is a glass on the table' is more acceptable than existential 'there is a table under the glass' because compared to table, glass can be assigned to an $\mathrm{F}$ role. The rationale for sagittal configurations comes from the fact that sagittality is one of the fundamental cognitive categories (e.g. Lyons 1977) which is mapped on the body and reflected in spatial relations and temporal relations (Evans 2006; Núñez and Sweetser 2006).

\section{Methodology}

Sixty-four native speakers of Turkish participated in this study. We created four scripts: Each script consisted of 24 items/sentences: 8 testing items (2 sets randomly selected from 8 token sets), 8 good fillers, 8 bad fillers. Scripts had a 7-point Likert scale (ratings between 0-6) with a $2 \times 2$ withinsubjects factorial design (F-Grelation $\mathrm{x}$ Sagittal). Below, we give a token set consisted of existential sentences with mouse and elephant for F-G relation and 'in front' and 'behind' for sagittal relations. We hypothesized (2) and (3) would be more acceptable than (4) and (5).

(2) Filin önünde bir fare var. ( $\mathrm{F}<\mathrm{G}$; in front) 'There is a mouse in front of an elephant'

(3) Filin arkasında bir fare var. ( $\mathrm{F}<\mathrm{G}$; behind)

'There is a mouse behind an elephant'

(4) Farenin önünde bir fil var. ( $F>G$; in front) 'There is an elephant in front of a mouse'

(5) Farenin arkasinda bir fil var. ( $\mathrm{F}>\mathrm{G}$; behind) 'There is an elephant behind a mouse' 


\section{Results}

Descriptive statistics of the measures are given below.

Table 1. Means and standard deviations of the factors and their levels.

\begin{tabular}{|l|l|l|}
\hline \hline & Mean & SD \\
\hline $\mathrm{F}>\mathrm{G}$, in front of & 3.77 & 1.76 \\
\hline $\mathrm{F}>\mathrm{G}$, behind & 4.39 & 1.70 \\
\hline $\mathrm{F}<\mathrm{G}$, in front of & 4.79 & 1.44 \\
\hline $\mathrm{F}<\mathrm{G}$, behind & 4.37 & 1.63 \\
\hline \hline
\end{tabular}

Repeated measures ANOVA indicated a main effect for the F-G relation, $\mathrm{F}(1,63)=11.27, \mathrm{p}<.05$ but not for the Sagittal, $\mathrm{F}(1,63)=.50, \mathrm{p}>.05$. Yet, there was an interaction, $\mathrm{F}(1,63)=8.01, \mathrm{p}<.05$. As we expected, this finding indicated that participants judged the $\mathrm{F}<\mathrm{G}$ sentences $(\mathrm{M}=4.58, \mathrm{SD}=0.16)$ with higher ratings compared to the $F>G$ sentences $(M=4.08, S D=0.17)$. As for interaction, they rated the $\mathrm{F}<\mathrm{G}$ sentences with in front of the highest $(\mathrm{M}=4.79, \mathrm{SD}=0.18)$ while the $\mathrm{F}>\mathrm{G}$ sentences with in front of the lowest $(\mathrm{M}=3.77, \mathrm{SD}=0.22)$.

\section{Conclusion}

According to Talmy (2000), Figure and Ground are two fundamental cognitive/semantic categories. From psycholinguistic studies, we have already known that assigning a Figure or Ground role to an entity is very important in the language of spatial expressions (e.g. Levinson 2003), in which constructing lateral and sagittal relations is essential (e.g. Lyons 1977). The present study has explored the relationship between these two categories, Figure and Ground, and sagittality by obtaining acceptability judgments from native Turkish speakers. These findings provided additional evidence for the F-G relations with sagittal configurations from Turkish existential sentences by using experimental linguistic methodology. Future research will investigate this issue in other languages.

\section{Acknowledgements}

This study supported in part by Işık University scientific research grant (BAP-12A103).

\section{References}

Enc, M. 1991. The semantics of specificity. The Linguistic Inquiry, 22, 1, 1-25.

Evans, V. 2006. The structure of time: Language, meaning, and temporal cognition. Philadelphia, PA, John Benjamins Publishing Company. 
Francez, I. 2009. Existentials, predication, and modification. Linguistics and Philosophy, 32, 1, 1-50.

Freeze, R. 1992. Existentials and other locatives. Language, 68, 3, 553-595.

Heim, I. 1987. Where does the definiteness restriction apply? Evidence from the definiteness of variables. In E. Reuland \& Al. G. B. ter Meulen (eds.) 1987, The Representation of (In)definitenesss, 21-42. Cambridge, MA, The MIT Press.

Keenan, E. L. 2003. The definiteness effect: Semantics or pragmatics? Natural Language Semantics 11, 187-216.

Levinson, S. C. 2003. Space in language and cognition: Explorations in cognitive diversity. Cambridge, UK, Cambridge University Press.

Lyons, J. 1977. Semantics. Cambridge, UK, Cambridge University Press.

McNally, L. 2011. Existential sentences. In C. Maienborn, Klaus von Heusinger \& Paul Portner (eds.) 2011, Semantics: An International Handbook of Natural Language Meaning, Volume: 2, 1829-1848. Berlin: de Gruyter.

Núñez, R., \& Sweetser, E. 2006. With the Future Behind Them: Convergent Evidence From Aymara Language and Gesture in the Crosslinguistic Comparison of Spatial Construals of Time. Cognitive Science, 30, 3, 401-450.

Svorou, S. 1994. The grammar of space. Amsterdam, NL, John Benjamins Publishing Company.

Talmy, L. 1987. Lexicalization patterns: Types and universals. Cognitive Science Report, 47. Cognitive Science Program, University of California, Berkeley.

Talmy, L. 2000. Toward a Cognitive Semantics (Vol. 1). Cambridge, MA, The MIT Press.

Zucchi, A. 1995. The ingredients of the definiteness and the definiteness effect. Natural Language Semantics, 3, 33-7. 